\title{
The Talent Identification of Kayak Athletes: A Research-based on Analytic Hierarchy Process
}

\author{
Syahid Nur Yasin 1,2, , Amung Ma’mun², Agus Rusdiana², Ade Gafar Abdullah², Lutfi Nur ${ }^{3}$ \\ ${ }^{1}$ Department of Physical Education Health and Recreation, STKIP Pasundan Cimahi, 40512, Cimahi, Indonesia \\ ${ }^{2}$ Department of Sports Education, School of Postgraduate Studies, Universitas Pendidikan Indonesia, 40154, Bandung, Indonesia \\ ${ }^{3}$ Department of Elementary Teacher Education, Tasikmalaya Campus, Universitas Pendidikan Indonesia, 40154, Bandung, Indonesia
}

Received September 9, 2020; Revised December 7, 2020; Accepted December 22, 2020

\section{Cite This Paper in the following Citation Styles}

(a): [1] Syahid Nur Yasin, Amung Ma'mun, Agus Rusdiana, Ade Gafar Abdullah, Lutfi Nur, "The Talent Identification of Kayak Athletes: A Research-based on Analytic Hierarchy Process," International Journal of Human Movement and Sports Sciences, Vol. 8, No. 6, pp. 395 - 402, 2020. DOI: 10.13189/saj.2020.080611.

(b): Syahid Nur Yasin, Amung Ma'mun, Agus Rusdiana, Ade Gafar Abdullah, Lutfi Nur (2020). The Talent Identification of Kayak Athletes: A Research-based on Analytic Hierarchy Process. International Journal of Human Movement and Sports Sciences, 8(6), 395 - 402. DOI: 10.13189/saj.2020.080611.

Copyright $\bigcirc 2020$ by authors, all rights reserved. Authors agree that this article remains permanently open access under the terms of the Creative Commons Attribution License 4.0 International License

\begin{abstract}
This research aimed to identify the talent needed by kayak athletes between 14-16 years old. Furthermore, the data gathered in this study would be analyzed by using the Analytic Hierarchy Process (AHP) in order to find out which element has significant roles in supporting kayak athletes. Mixed-Method Research (MMR) was employed in this research by using a literature study and administering a questionnaire to 32 professional coaches consisting of twenty eight male and four female coaches. The rationale for selecting these coaches is to identify their opinions regarding the talent criteria of selecting kayak athletes. The result of the analysis showed that there were five parameters that could be used to identify the talent of kayak athletes, such as anthropometry (height and weight), biomechanics (endurance and strength), psychology (self-confidence and focus), special endurance (aerobic and anaerobic; physiology), and skills (catch and pull-push). This talent identification model provides information for coaches, athletes, and parents to find out the talent of kayak athletes.
\end{abstract}

Keywords Kayak, Talent Identification, Analytic Hierarchy Process (AHP)

\section{Introduction}

Talent Identification (TI) of athletes is the first step and becomes an essential element in building sports achievement. [1]. There is a different approach in identifying talent among many kinds of sports; for example, group sports are much more complicated than individual sports like running, cycling, kayak, etc. [2]. Talent identification and development for individual sports such as lifting, cycling, kayak, and athletic is done through special anthropometry and physiology. [3]. In relation to rivalry, sports achievement coaching keeps getting pressure to produce new approaches on how to identify talent (TI). Previous researches mentioned that the TI program is designed to recognized natural talents [4], or high-quality ability [5], or identify young athletes who have extraordinary talent in senior elite sport, then recruit them [6]. However, there is still a challenge of such a program. It is to develop a special test design that is valid and reliable to examine young athletes' ability in a particular sport, and also to accelerate its development and to provide good predictive scores for future success. [7][9].

Success predictors in talent identification (TI) cannot be determined based on one dimension only [10]; however, the process of TI must be carried out in a multidiscipline and comprehensive manner. Therefore, TI's testing process is focused on physical testing and continued by tactically skilled tests from other disciplines such as psychology and sociology. [11]. The psychological analysis carried out to Olympic athletes revealed that the athletes are highly confident, mentally tough, highly 
sportive, smart, optimistic, perfectionist, competitive, hardworking, coachable, and able to overcome their anxiety, focused on managing and reaching, and having a hopeful disposition. [12]. Important sociological factors that influence talent development have to do with the environment, institutions, coaches and fellow athletes. These sociological factors influence athletes' decision making, motivation, habits, training, and skills development [13]-[15]. Research on social influences in sport also provides evidence that parents, coaches and fellow athletes have an impact on athletes which varies in relative age [16]. However, this contrasts with traditional talent identification models which cannot provide a holistic picture of the psychological characteristics of champions and do not understand the social impact of peers, culture, media and other competitive activities [12]. The reason for this deficiency is the validity of existing tests, which are still bias. In short, we still have to face many difficulties in determining scientific, medical, psychological, and social criteria, even though several pieces of research had been carried out for decades. Hence, specific research on identification in certain sports is needed to obtain detailed information to identify the individuals' potential in certain sports.

Anthropometric indicator in identifying talent has an essential role for young athletes to move towards the world's elite athletes. In line with this, a recent study by [17] explained that the anthropometric characteristics of elite male and female paddlers aged 13-14 years are useful for talent identification. Anthropometric data are useful because several anthropometric variables are correlated with the performance [18]-[20]. The trainer can also use the anthropometric variable to control the training process and to select the proper paddling and boat arrangement [21]. Comprehensive anthropometric descriptions can help coaches better understand and select their athletes.

Specific physiological indicators are also suitable for identifying talent in kayak athletes. The "physiology" indicator in identifying talent is the indicator of all organs' functions that supports the human movement. The "physiology" sub-indicators that strongly support the performance of kayak athletes are aerobic endurance, aerobic capacity, and anaerobic capacity [7], [22]-[26]. As kayaking is an outdoor sport or sport done in nature, it has a character that prioritizes physical ability with aerobic endurance as the dominant element up to $50 \%$ [27]. Apart from the aerobic system's contribution, kayak sports, also benefit from a higher anaerobic capacity. Indeed, kayak exercise intensity is usually contested above the lactate threshold. This condition suggests that energy is also provided from non-oxidative sources [28]. Besides, several studies have shown that anaerobic capacities such as peak power, total workforce, and peak lactate concentrations in an "all-out" 30s effort on an ergometer kayak have a large to massive correlation with 200, 500, and 1000-m performance above water [19], [29]. These findings collectively suggest that aerobic and anaerobic systems and morphological characteristics are important for enhancing kayak athletes' performance [31]. Hence, the "physiology" indicator needs to be in the identification of talent for kayak athletes. However, it is reasonable to assume that other factors also contribute to kayak athlete performance.

In rowing, there are two numbers to be contested, the Olympic and Traditional numbers. The Olympic number consists of two types, namely Rowing and Canoeing. At the same time, the traditional number includes the traditional boat race or is also known as the Dragon Boat which is headquartered to international agencies, namely the International Dragon Boat Federation (IDBF) and International Canoe Federation (ICF). Canoeing Olympic number consists of Kayak and Canoe and has been recognized by an international body, namely the ICF. Sports talent is essential in improving sports performance. The coaching process that is not in line with the athlete's talent will not achieve optimal performance. The selection of talent identification (IF) methods is needed as a basis to identify the individual abilities of athlete candidates.

Analytic Hierarchy Process (AHP) is a method in dealing with a complex problem according to the interactions on the problem itself [31]. AHP can help set priorities and make decisions that should consider qualitative and quantitative aspects [32]. A hierarchy allows the breakdown of complex or unstructured problems into sub-problems, then arranges them into a hierarchical form [33] so that the AHP can help in making complex and unstructured decisions into groups. Then organize the groups into the form of criteria levels, then enter a numerical value instead of human perception in relative comparisons. With the synthesis, it will be able to determine the elements of the highest priority. Research on using the AHP model has been carried out many times, especially in management, to see workers' talents. However, there have not been many studies that have applied it to sports, especially in kayaking; therefore, the study intends to reveal the kayaking athletes' talents identification using AHP. The importance of revealing how to identify talent in rowing for competition numbers like kayaking is very much needed to help coaches, players, and parents understand the talent for prospective athletes. Therefore, this study seeks to analyze the components that play a role in identifying kayak athletes' talent by applying the Analytic Hierarchy Process.

\section{Materials and Methods}

\subsection{Design}

The type of mixed-method research design used in this study is exploratory sequential mixed. In the exploratory sequential design, the collection of qualitative and quantitative data is carried out in two stages, and the main emphasis is on qualitative data [34], [35]. In this study, qualitative data collection and analysis were carried out by 
conducting systematic literature reviews and tracing expert opinions regarding indicators in identifying kayak athletes' talent.

\subsection{Multi-criteria Analysis Decision Analysis}

Multi-criteria Analysis Decision Analysis (MCDA) is a set of systematic and analytical procedures for making decisions, such as classification, sorting, and ranking. It is usually used to help experts and decision-makers find solutions to complex multi-criteria problems. It has been widely applied in science and industry since it can improve quality decisions by making processes more explicit, rational, and efficient [36]. MDCA has some methods and tools, and one of them is the Analytic Hierarchy Process (AHP) approach. The approach adopted in this study is due to its capability to decompose a complex problem into a manageable hierarchy, to ensure a detailed examination using pair-wise comparisons at each level, and to obtain a single decision output. In this study, the AHP model was developed to rank the talent identification process criteria among kayakers.

\subsection{Sample Characteristics}

Indonesian kayaker coaches $(n=32$, aged 22-32 years old) participated in this study and were selected based on the purposive sampling technique. The coaches who have obtained a kayak coaching license and taken part in talent identification for junior kayakers were selected. The majority of them $(68.8 \%)$, have more than five-year coaching experience and have participated in international coaching training. Half of the participants $(56.3 \%)$ have coaching experience at the international level.

\subsection{Data Collection and Analysis}

The researcher looked for references on the factors that affect kayak athletes' performance through online reference sources. It aimed to compile indicators and sub-indicators, then obtained 53 Scopus indexed journal articles without filters of the year they were published, which focused their studies on the characteristics of the sport of kayaking. The inclusion criteria relate to articles closely related to the identification of talents for kayaking at various ages. Meanwhile, the exclusion criteria are articles that do not clearly describe the sample, method, and results of the research that has been carried out. This literature review process produced five indicators, and twenty sub-indicators needed to identify the talents of Kayak athletes. After that, the criteria and sub-criteria factors were grouped, as shown in table 1 . Then the researcher made an online questionnaire via Google Form to rank the criteria or requirements for identifying kayaking talent, which was in line with the multi-criteria at the international level, which was distributed to research participants. The five criteria identified were anthropometry, physiology, biomechanics, skills, and psychology. These five criteria were used in determining the priority scale of the criteria and were used as an alternative to achieve the design goals of identifying talent for kayak athletes. The data analysis technique used to determine the priority of elements in a decision making and employed a pairwise comparisons matrix.

\section{Results and Discussions}

This study aimed to analyze the components that play a role in identifying kayak athletes' talents by applying the Analytic Hierarchy Process (AHP). The results of the questionnaire given to experts, in this case, experienced Indonesian coaches, provide an overview of the ranking of indicators in identifying talents of kayak athletes as shown in table 3 . 
Table 1. Criteria and sub-criteria used in evaluating kayaking talent identification

\begin{tabular}{|c|c|c|}
\hline Criteria & Sub-criteria & Reference \\
\hline \multirow{6}{*}{ Anthropometry } & Weight & $\begin{array}{c}\text { (Boegman \& Dziedzic, 2016; } \\
\text { López-plaza, Alacid, Muyor, \& López-miñarro, 2017; } \\
\text { Michael, Rooney, \& Smith, 2008) }\end{array}$ \\
\hline & Height & (Boegman \& Dziedzic, 2016; López-plaza et al., 2017; Michael, Smith, \& Rooney, 2009; Yasin, 2019b) \\
\hline & Arm span & (Aitken \& Jenkins, 1998, 2010; Hugo, 2004; López-plaza et al., 2017; Yasin, 2019b) \\
\hline & Limb length & (Aitken \& Jenkins, 1998, 2010; Hugo, 2004; López-plaza et al., 2017; Yasin, 2019b) \\
\hline & Sitting height & (Burke, 1976; Hagner-Derengowska et al., 2014; Ong et al., 2006; Tanner \& Gore, 2012; Yasin, 2019b) \\
\hline & Shoulder width & (Ho, Smith, \& O’Meara, 2009; Ong et al., 2006; Yasin, 2019b) \\
\hline \multirow{4}{*}{ Physiology } & Aerobic Endurance & $\begin{array}{c}\text { (Boegman \& Dziedzic, 2016; Burke, 1976; Döring et al., 2010; Howell \& Coupe, 1964; Lidor et al., 2009; Pripstein, Rhodes, McKenzie, \& } \\
\text { Coutts, 1999; Tanner \& Gore, 2012; Yasin, 2019b) }\end{array}$ \\
\hline & Aerobic Capacity & $\begin{array}{l}\text { (Borges, Dascombe, Bullock, \& Coutts, 2015; López-Plaza et al., 2017; Pripstein et al., 1999; Smith, Doherty, Drake, \& Price, 2004; Yasin, } \\
\text { 2019a, 2019b) }\end{array}$ \\
\hline & Anaerobic Capacity & (Borges et al., 2015; López-Miñarro et al., 2013; López-Plaza et al., 2017; McKean \& Burkett, 2014; Yasin, 2019b) \\
\hline & Nutrition & (Boegman \& Dziedzic, 2016; Stellingwerff, Maughan, \& Burke, 2011) \\
\hline \multirow{4}{*}{ Biomechanics } & $\begin{array}{l}\text { Maximum Strength Bench Press - } 1 \\
\text { RM }\end{array}$ & (Lawton, Cronin, \& Mcguigan, 2012; McDonnell, Hume, \& Nolte, 2013; Singh, Singh, \& Sirisinghe, 1995; Tanner \& Gore, 2012) \\
\hline & $\begin{array}{l}\text { Maximum Strength Bench Pull - } 1 \\
\text { RM }\end{array}$ & (Ho et al., 2009; Lawton et al., 2012; McKean \& Burkett, 2014; Yasin, 2019a) \\
\hline & $\begin{array}{l}\text { Maximum Endurance Bench Press - } \\
\text { 2x1 minute }\end{array}$ & (Aitken \& Jenkins, 1998; Kennedy \& Bell, 2003; López-Plaza et al., 2017; M. Roth, 2012; Ward et al., 2017) \\
\hline & $\begin{array}{l}\text { Maximum Endurance Bench Pull - } \\
\text { 2x1 minute }\end{array}$ & (Lippi, Longo, \& Maffulli, 2010; M. Roth, 2012; Singh et al., 1995; Ward et al., 2017; Yasin, 2019a) \\
\hline \multirow{3}{*}{ Skills } & Catch & (Ho et al., 2009; Lawton et al., 2012; Ong et al., 2006; Zahálka, Malý, Malá, Doktor, \& Větrovský, 2011) \\
\hline & Pull-Push & (Ho et al., 2009; Lawton et al., 2012; Ong et al., 2006; Zahálka et al., 2011) \\
\hline & Recovery & (Ho et al., 2009; Lawton et al., 2012; Ong et al., 2006; Zahálka et al., 2011) \\
\hline \multirow{4}{*}{ Psychology } & Self-confidence & (A. Abbott, Button, Pepping, \& Collins, 2005; Button, 2011; Gould et al., 2002; Kreiner-phillips \& Orlick, 1993) \\
\hline & Motivation & (A. Abbott et al., 2005; Boegman \& Dziedzic, 2016; Gould et al., 2002; Wisløff, Castagna, Helgerud, Jones, \& Hoff, 2004) \\
\hline & Focus & (A. Abbott et al., 2005; Boegman \& Dziedzic, 2016; Gould et al., 2002; Wisløff et al., 2004) \\
\hline & Endurance to stress & (Gould et al., 2002; Michael et al., 2009; Reilly et al., 2000) \\
\hline
\end{tabular}

Table 2. Characteristics of kayak coaches participating in this study (Indonesia)

\begin{tabular}{|c|c|c|c|c|c|c|c|c|c|c|c|c|c|c|c|c|}
\hline \multirow{2}{*}{$\begin{array}{c}\text { Social } \\
\text { demo-graphics }\end{array}$} & \multicolumn{2}{|c|}{ Sex } & \multicolumn{3}{|c|}{ Age } & \multicolumn{4}{|c|}{ Coaching experience (years) } & \multicolumn{3}{|c|}{ Educational background } & \multicolumn{2}{|c|}{$\begin{array}{c}\text { International } \\
\text { coaching training }\end{array}$} & \multicolumn{2}{|c|}{ Coaching experience } \\
\hline & Male & Female & $22-27$ & $27-32$ & $>32$ & $<1$ & $1-3$ & $3-5$ & $>5$ & $\begin{array}{c}\text { High } \\
\text { school }\end{array}$ & Bachelor & Master & No & Yes & National & $\begin{array}{c}\text { Interna-tio } \\
\text { nal }\end{array}$ \\
\hline $\mathrm{N}$ & 28 & 4 & 2 & 7 & 23 & 1 & 5 & 4 & 22 & 14 & 15 & 3 & 10 & 22 & 14 & 18 \\
\hline$\%$ & 87.5 & 12.5 & 6.3 & 21.9 & 71.8 & 3.1 & 15.6 & 12.5 & 68.8 & 43.8 & 46.9 & 9.4 & 31.25 & 68.75 & 43.7 & 56.3 \\
\hline
\end{tabular}


Table 3. Recapitulation of ranking indicators according to experts (coaches)

\begin{tabular}{|c|c|c|c|c|c|c|c|}
\hline \multirow{2}{*}{$\mathrm{N}$} & \multirow{2}{*}{ Criteria } & \multicolumn{6}{|c|}{ Rank } \\
\hline & & 1 & 2 & 3 & 4 & 5 & 6 \\
\hline \multirow{5}{*}{32} & Anthropometry & Height & Arm Span & Weight & Body Length & $\begin{array}{l}\text { Shoulder } \\
\text { Width }\end{array}$ & $\begin{array}{l}\text { Limb } \\
\text { Length }\end{array}$ \\
\hline & Physiology & $\begin{array}{c}\text { Aerobic } \\
\text { Endurance }\end{array}$ & $\begin{array}{l}\text { Aerobic } \\
\text { Capacity }\end{array}$ & $\begin{array}{l}\text { Anaerobic } \\
\text { Capacity }\end{array}$ & & & \\
\hline & Biomechanics & $\begin{array}{c}\text { Maximum } \\
\text { Strength-Bench } \\
\text { Press } \\
\end{array}$ & $\begin{array}{c}\text { Maximum } \\
\text { Strength-Bench } \\
\text { Pull } \\
\end{array}$ & $\begin{array}{c}\text { Maximum } \\
\text { Endurance-Bench } \\
\text { Press } \\
\end{array}$ & $\begin{array}{c}\text { Maximum } \\
\text { Endurance-Bench } \\
\text { Pull } \\
\end{array}$ & & \\
\hline & Skills & Catch & Pull-Push & Recovery & & & \\
\hline & Psychology & Self-confidence & Motivation & Focus & $\begin{array}{c}\text { Resistant to } \\
\text { Fatigue and Stress }\end{array}$ & & \\
\hline
\end{tabular}

Table 4. The Comparison of the main objective indicator pair matrix with priority weights

\begin{tabular}{|c|c|c|c|c|c|c|}
\hline & Antropometry & Physiology & Biomechanics & Skills & Psychology & Priority Weights \\
\hline Anthropometry & 1.00 & 1.00 & 0.33 & 0.50 & 0.33 & 0.221 \\
\hline Physology & 1.00 & 1.00 & 0.25 & 0.33 & 0.33 & 0.221 \\
\hline Biomechanics & 3.00 & 4.00 & 1.00 & 0.50 & 3.00 & 0.072 \\
\hline Skills & 2.00 & 3.00 & 1.00 & 1.00 & 0.33 & 0.440 \\
\hline Psychology & 3.00 & 3.00 & 1.00 & 0.33 & 1.00 & 0.046 \\
\hline \multicolumn{7}{|c|}{ CR $\mathbf{0 . 0 2}<0.10$ (accepted) } \\
\hline
\end{tabular}

Table 3 shows the ranking order of the essential components from rank 1 to the last rank in each of the sub-criteria components based on the opinions of 32 experts who are experienced kayak trainers. Furthermore, to calculate the priority weight in this study, we used the consistency principle. The consistency principle was used to measure the level of inconsistency, which was measured by the consistency ratio (CR), giving priority weight is considered consistent if the $\mathrm{CR}$ value is less than 0.10 . The results of the comparison of the main objective indicator pair matrix with priority weights, are as shown in table 4.

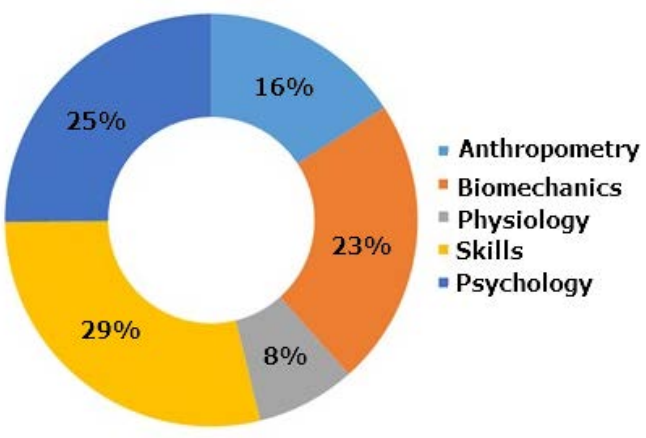

Figure 1. Weight priority identification of talent kayak athletes

Figure 1 shows the priority weights for kayak athlete talent identification, which shows that the "Skills" indicator is the indicator that has the actual weight that needs to be in the talent identification model for kayak athletes. Furthermore, the "psychology" indicator is in the next priority weight that is important to identify kayak athletes' talent. Likewise, the "biomechanics" indicator has a goal priority weight level of $22 \%$, meaning that this indicator is important enough to be considered in the kayak athletes' talent identification model. Meanwhile, the "anthropometric" indicator has a percentage weight of $18 \%$ as an indicator to measure talent identification. Likewise, the "physiology" indicator contributes to a weight of $8 \%$ as an indicator that needs to be used to identify kayak athletes' talent.

Identifying individuals with the most significant potential to excel in sport presents a significant and relevant challenge for governments, coaches, and funding teams. With limited resources to help athletes develop themselves, effective talent identification should minimize errors to advance to the talent development stage. In building an effective talent identification model, coaches and funding agencies need to recognize the multidimensional and dynamic nature of sporting talent and promote the various factors that enable athletes to develop into successful elite players.

This research was the first to be conducted in analyzing the talent needs of kayaking athletes by applying the AHP system. Based on the research results, the priority weights in the AHP model could be used to precisely analyze what needs are required by analysts, such as research on identifying employee talents in companies, for example, research on the application of multi-criteria decision analysis methods into the talent identification process concludes the effectiveness of the AHP model in 
identifying employee talent in a company [36]. Besides, the AHP model has also been applied in determining the key to the success of Chinese men's basketball team development, and the results show that improving the training ability of the CBA league for the new generation of Chinese players is the key to the development of the Chinese men's basketball team [66].

In various individual sports, the talent identification process is usually carried out traditionally by looking at various factors that match the coach's criteria; for example, a prospective athlete is talented in his/her field [67]. Besides, the talent identification process that was carried out did not describe each sport's percentage weight. This study's results offer coaches, especially those involved in kayaking, to pay attention to the percentage of priority weights such as skills, psychology, biomechanics, anthropometry, and physiology.

\section{Conclusions}

This research has helped create a practical model for promoting the talent identification that coaches can undertake. The selection of indicators and sub-indicators in identifying athletes' talents was made through a literature review that produced five leading indicators: anthropometry, physiology, biomechanics, skills, and psychology, and 20 sub-indicators. The expert team, in this case, kayak trainers, gives rankings on each indicator and sub-indicator to obtain an overview of the indicators and sub-indicators that are deemed most suitable for conducting a talent identification test. Weighting the leading indicators and sub-indicators' priority using the analytical hierarchy process (AHP) provides the trainer with understanding in using an efficient talent identification test. Besides, this research is also not free from shortcomings. The shortcoming in this study is the experts or the trainers involved as expert judgment comes from Indonesia. It means that the priority weight model with AHP is not necessarily the same as other countries and requires further research.

\section{REFERENCES}

[1] B. Falk, R. Lidor, Y. Lander, and B. Lang, "Talent identification and early development of elite water-polo players : a 2-year follow-up study," J. Sports Sci., vol. 22, no. 4, pp. 347-355, 2004

[2] T. Reilly, A. M. Williams, A. Nevill, and A. Franks, "A multidisciplinary approach to talent identification in soccer," J. Sports Sci., vol. 18, no. 9, pp. 695-702, 2000.

[3] D. G. Hoare, "Predicting success in junior elite basketball players--the contribution of anthropometic and physiological attributes.," J. Sci. Med. Sport, vol. 3, no. 4, pp. 391-405, 2000.
[4] S. Breitbach, S. Tug, and P. Simon, "Conventional and Genetic Talent Identification in Sports: Will Recent Developments Trace Talent?," Sport. Med., vol. 44, no. 11, pp. 1489-1503, 2014.

[5] D. T. Pearson, G. A. Naughton, and M. Torode, "Predictability of physiological testing and the role of maturation in talent identification for adolescent team sports," J. Sci. Med. Sport, vol. 9, no. 4, pp. 277-287, 2006.

[6] R. Vaeyens, A. Güllich, C. R. Warr, and R. Philippaerts, "Talent identification and promotion programmes of Olympic athletes," J. Sports Sci., vol. 27, no. 13, pp. 1367$1380,2009$.

[7] R. Lidor, J. Côté, and D. Hackfort, "ISSP position stand: To test or not to test? The use of physical skill tests in talent detection and in early phases of sport development," Int. J. Sport Exerc. Psychol., vol. 7, no. 2, pp. 131-146, 2009.

[8] D. M. de Haan, "A Review of the Appropriateness of Existing Micro-and Meso-level Models of Athlete Development within Equestrian Sport," International Journal of Human Movement and Sports Sciences, vol. 5, no. 1 , pp. $1-8,2017$.

[9] Ö. Kaynar, "Investigation of the effects of the talent identification tests used by the coaches in wrestling on success," Universal Journal of Educational Research, vol. 7, no. 3, pp. 885-891, 2019.

[10] A Abbott and D. Collins, "A theoretical and empirical analysis of a 'state of the art' talent identification model," High Abil. Stud., vol. 13, no. 2, pp. 157-178, 2002.

[11] D. J. Burgess and G. A. Naughton, "Talent Development in Adolescent Team Sports: A Review.," Int. J. Sport. Physiol. Perform., vol. 5, no. 1, pp. 103-116, 2010.

[12] D. Gould, K. Dieffenbach, and A. Moffett, "Psychological Characteristics and Their Development in Olympic Champions," J. Appl. Sport Psychol., vol. 14, no. 3, pp. 172 204, Jan. 2002.

[13] S. M. Balish, M. A. Eys, and A. I. Schulte-Hostedde, "Evolutionary sport and exercise psychology: Integrating proximate and ultimate explanations," Psychol. Sport Exerc., vol. 14 , no. 3, pp. 413-422, 2013.

[14] L. Nur, P. M. Setiadi, Y. Kusdinar, and A. A. Malik, "Electronic rubric for motivation in physical education," $J$. Phys. Conf. Ser., vol. 1318, p. 12129, Oct. 2019.

[15] A. Rokhayati, L. Nur, E. Elan, and G. Gandana, "Tactical Approach to Increase Motivation for Learning Students on Physical Education Teaching in Primary Schools Tactical Approach to Increase Motivation for Learning Students on Physical Education Teaching in Primary Schools," in IOP Conference Series: Materials Science and Engineering.

[16] D. J. Hancock, A. L. Adler, and J. Côté, "A proposed theoretical model to explain relative age effects in sport," Eur. J. Sport Sci., vol. 13, no. 6, pp. 630-637, 2013.

[17] F. Alacid, M. Marfell-Jones, P. López-Miñarro, I. Martínez, and J. Muyor, "Morphological characteristics of young elite paddlers,” J. Hum. Kinet., vol. 27, no. 1, pp. 95-110, 2011.

[18] R. W. Fry and A. R. Morton, "Physiological and kinanthropometric attributes of elite flatwater kayakists.," 
Med. Sci. Sports Exerc., vol. 23, no. 11, pp. 1297-1301, 1991.

[19] K. Van Someren and G. S. Palmer, "Prediction of 200-m sprint kayaking performance," Can. J. Appl. Physiol., vol. 28, no. 4, pp. 505-517, 2003.

[20] A. A. Malik and L. Nur, "The Effectiveness of Using Computer Integrated Anthropometry and Vertical Jump as Measuring Device," International Journal of Human Movement and Sports Sciences, vol. 8, no. 5, pp. 161-165, 2020.

[21] K. Ong, B. Elliott, T. Ackland, and A. Lyttle, "Performance tolerance and boat set - up in elite sprint Kayaking," Sport. Biomech., vol. 5, no. 1, pp. 77-94, 2006.

[22] S. Boegman and C. E. Dziedzic, "Nutrition and Supplements for Elite Open-Weight Rowing," Curr. Sports Med. Rep., vol. 15, no. 4, pp. 252-261, 2016.

[23] R. K. Tanner and C. J. Gore, Physiological Tests for Elite Athletes. 2012.

[24] F. E. Döring et al., "Actn3 r577x and other polymorphisms are not associated with elite endurance athlete status in the Genathlete study," J. Sports Sci., vol. 28, no. 12, pp. 13551359, 2010.

[25] D. López-Plaza, F. Alacid, J. M. Muyor, and P. Á. López-Miñarro, "Sprint kayaking and canoeing performance prediction based on the relationship between maturity status, anthropometry and physical fitness in young elite paddlers," J. Sports Sci., vol. 35, no. 11, pp. 1083-1090, 2017.

[26] M. R. McKean and B. J. Burkett, "The influence of upper-body strength on flat-water sprint kayak performance in elite athletes," Int. J. Sports Physiol. Perform., vol. 9, no. 4, pp. 707-714, 2014.

[27] W. C. Byrnes, "Aerobic and anaerobic contributions during simulated canoe/kayak sprint events," Med. Sci. Sport. Exerc., vol. 29, no. 5, p. S220, 1997.

[28] K. A. Von Someren, G. R. W. Phillips, and G. S. Palmer, "Comparison of physiological responses to open water kayaking and kayak ergometry," Int. J. Sports Med., vol. 21, no. 03, pp. 200-204, 2000.

[29] K. A. van Someren and G. Howatson, "Prediction of flatwater kayaking performance," Int. J. Sports Physiol. Perform., vol. 3, no. 2, pp. 207-218, 2008.

[30] P. Zamparo, C. Capelli, and G. Guerrini, "Energetics of kayaking at submaximal and maximal speeds," Eur. J. Appl. Physiol. Occup. Physiol., vol. 80, no. 6, pp. 542-548, 1999.

[31] G. Budak, İ. Kara, and Y. T. İç, "Weighting the Positions and Skills of Volleyball Sport by Using AHP : A real life application Weighting the Positions and Skills of Volleyball Sport by Using AHP : A real life application," no. February, 2017.

[32] C. Wedley, "Combining Qualitative and Quantitative Analytic Hierarchy Approach,” no. 2, pp. 57-64, 1990.

[33] I. Erol and W. G. F. Jr, "A methodology for selection problems with multiple, conflicting objectives and both qualitative and quantitative criteria," vol. 86, pp. 187-199, 2003.
[34] I. Newman, J. Lim, and F. Pineda, "Content validity using a mixed methods approach: Its application and development through the use of a table of specifications methodology," $J$. Mix. Methods Res., vol. 7, no. 3, pp. 243-260, 2013.

[35] K. Diehl, A. K. Fuchs, K. Rathmann, and J. Hilger-Kolb, "Students' motivation for sport activity and participation in university sports: A mixed-methods study," Biomed Res. Int., vol. 2018, 2018.

[36] Y.-L. Lai and A. Ishizaka, "The application of multi-criteria decision analysis methods into talent identification process: A social psychological perspective," J. Bus. Res., vol. 109, pp. 637-647, 2020.

[37] J. S. Michael, K. B. Rooney, and R. Smith, "The metabolic demands of kayaking : A review," vol. 2, no. October 2007, pp. 1-7, 2008.

[38] D. López-plaza, F. Alacid, J. M. Muyor, and P. Á. López-miñarro, "Differences in Anthropometry , Biological Age and Physical Fitness Between Young Elite Kayakers and Canoeists by," J. Hum. Kinet., vol. 57, no. 1, pp. 181190, 2017.

[39] J. S. Michael, R. Smith, and K. B. Rooney, "Determinants of kayak paddling performance," Sport. Biomech., vol. 8, no. 2, pp. 167-179, 2009.

[40] S. N. Yasin, "Performance Profile of Kayaker Team Indonesia,” vol. 11, no. Icsshpe 2018, pp. 117-119, 2019.

[41] D. A. Aitken and D. G. Jenkins, "Anthropometric-based selection and sprint kayak training in children," J. Sports Sci., vol. 16 , no. 6, pp. 539-543, 1998.

[42] D. A. Aitken and D. G. Jenkins, "Journal of Sports Sciences Anthropometric-based selection and sprint kayak training in children Anthropometric-based selection and sprint kayak training in children," no. October 2014, pp. 37-41, 2010.

[43] K. Hugo, "A Model for Talent Identification and Development for Team Sports in South Africa," A Model Talent Identif. Dev. Team Sport. South Africa, no. December, p. 134, 2004.

[44] E. J. Burke, "Validity of selected laboratory and field tests of physical working capacity," Res. Q. Am. Alliance Heal. Phys. Educ. Recreat., vol. 47, no. 1, pp. 95-104, 1976.

[45] M. Hagner-Derengowska et al., "Body structure and composition of canoeists and kayakers : analysis of junior and teenage polish national canoeing team," Biol. Sport, vol. 31, no. 4, pp. 323-326, 2014.

[46] S. R. Ho, R. Smith, and D. O'Meara, "Biomechanical analysis of dragon boat paddling: a comparison of elite and sub-elite paddlers," J. Sports Sci., vol. 27, no. 1, pp. 37-47, 2009.

[47] M. L. Howell and K. Coupe, "Effect of blood loss upon performance in the balke-ware treadmill test," Res. Quarterly. Am. Assoc. Heal. Phys. Educ. Recreat., vol. 35, no. 2, pp. 156-165, 1964.

[48] L. P. Pripstein, E. C. Rhodes, D. C. McKenzie, and K. D. Coutts, "Aerobic and anaerobic energy during a 2-km race simulation in female rowers," Eur. J. Appl. Physiol. Occup. Physiol., vol. 79, no. 6, pp. 491-494, 1999. 
[49] S. N. Yasin, "Contribution of Biomotoric Components to the Performance Athletes Number Canoeing 1000 Meter," vol. 11, no. Icsshpe 2018, pp. 97-99, 2019.

[50] P. M. Smith, M. Doherty, D. Drake, and M. J. Price, "The influence of step and ramp type protocols on the attainment of peak physiological responses during arm crank ergometry," Int. J. Sports Med., vol. 25, no. 08, pp. 616-621, 2004 .

[51] T. O. Borges, B. Dascombe, N. Bullock, and A. J. Coutts, "Physiological characteristics of well-trained junior sprint kayak athletes," Int. J. Sports Physiol. Perform., vol. 10, no. 5, pp. 593-599, 2015.

[52] P. Á. López-Miñarro, J. M. Muyor, F. Alacid, R. Vaquero-Cristóbal, D. López-Plaza, and M. Isorna, "Comparison of hamstring extensibility and spinal posture between kayakers and canoeists," Kinesiol. Int. J. Fundam. Appl. Kinesiol., vol. 45, no. 2, pp. 163-170, 2013.

[53] T. Stellingwerff, R. J. Maughan, and L. M. Burke, "Nutrition for power sports: middle-distance running, track cycling, rowing, canoeing/kayaking, and swimming," J. Sports Sci., vol. 29, no. sup1, pp. S79-S89, 2011.

[54] L. K. McDonnell, P. A. Hume, and V. Nolte, "A deterministic model based on evidence for the associations between kinematic variables and sprint kayak performance," Sport. Biomech., vol. 12, no. 3, pp. 205-220, 2013.

[55] T. W. Lawton, J. B. Cronin, and M. R. Mcguigan, "Anthropometry, strength and benchmarks for development: A basis for junior rowers' selection?," J. Sports Sci., vol. 30, no. 10, pp. 995-1001, 2012.

[56] R. Singh, H. J. Singh, and R. G. Sirisinghe, "Physical and physiological profiles of Malaysian dragon boat rowers.," $\mathrm{Br}$. J. Sports Med., vol. 29, no. 1, pp. 13-15, 1995.

[57] J. K. Ward et al., “A Sport Education Fitness Season's Impact on Students' Fitness Levels, Knowledge, and
In-Class Physical Activity," Res. Q. Exerc. Sport, vol. 88, no. 3, pp. 346-351, 2017.

[58] S. M. Roth, "Critical Overview of Applications of Genetic Testing in Sport Talent Identification," Recent Pat. DNA Gene Seq., vol. 6, no. 3, pp. 247-255, 2012.

[59] M. D. Kennedy and G. J. Bell, "Development of race profiles for the performance of a simulated 2000-m rowing race," Can. J. Appl. Physiol., vol. 28, no. 4, pp. 536-546, 2003.

[60] G. Lippi, U. G. Longo, and N. Maffulli, "Genetics and sports," Br. Med. Bull., vol. 93, no. 1, pp. 27-47, 2010.

[61] F. Zahálka, T. Malý, L. Malá, M. Doktor, and J. Větrovský, "Kinematic analysis of canoe stroke and its changes during different types of paddling pace-case study," J. Hum. Kinet., vol. 29, no. 2011, pp. 25-33, 2011.

[62] A. Abbott, C. Button, G. Pepping, and D. Collins, "Unnatural selection: Talent identification and development in sport," Nonlinear Dynamics. Psychol. Life Sci., vol. 9, no. 1, pp. 61-88, 2005.

[63] A. Button, Aims, principles and methodologies in talent identification and development. Elsevier Ltd., 2011.

[64] K. Kreiner-phillips and T. Orlick, "Winning After Winning: The Psychology of Ongoing Excellence," Sport Psychol., vol. 7, no. 1988, pp. 31-48, 1993.

[65] U. Wisløff, C. Castagna, J. Helgerud, R. Jones, and J. Hoff, "Strong correlation of maximal squat strength with sprint performance and vertical jump height in elite soccer players," Br. J. Sports Med., vol. 38, no. 3, pp. 285-288, 2004.

[66] H. Jiang, "Chinese mens basketball team development countermeasure research based on analytic hierarchy process," J. Chem. Pharm. Res, vol. 6, no. 5, pp. 1929-1936, 2014.

[67] K. Johnston, N. Wattie, J. Schorer, and J. Baker, "Talent identification in sport: a systematic review," Sport. Med., vol. 48, no. 1, pp. 97-109, 2018. 